\title{
Oscillometry complements spirometry in evaluation of subjects following toxic inhalation
}

\author{
Kenneth I. Berger ${ }^{1,2,5}$, Meredith Turetz ${ }^{1,5}$, Mengling Liu ${ }^{3}$, Yongzhao Shao ${ }^{3}$, \\ Angeliki Kazeros ${ }^{1}$, Sam Parsia ${ }^{1}$, Caralee Caplan-Shaw ${ }^{1}$, Stephen M. Friedman ${ }^{4}$, \\ Carey B. Maslow ${ }^{4}$, Michael Marmor ${ }^{3}$, Roberta M. Goldring ${ }^{1,2}$ and \\ Joan Reibman ${ }^{1}$
}

Affiliations: 'Dept of Medicine, Division of Pulmonary, Critical Care and Sleep Medicine, New York University School of Medicine, New York, NY, USA. ${ }^{2}$ André Cournand Pulmonary Physiology Laboratory, Bellevue Hospital, New York, NY, USA. ${ }^{3}$ Department of Population Health, New York University School of Medicine, New York, NY, USA. ${ }^{4}$ New York City Department of Health and Mental Hygiene, New York, NY, USA. ${ }^{5}$ These authors contributed equally to this manuscript.

Correspondence: Joan Reibman, New York University School of Medicine, 550 1st Avenue, Room NB7N24, New York, NY 10016, USA. E-mail: joan.reibmananyumc.org

ABSTRACT The World Trade Center (WTC) destruction released dust and fumes into the environment. Although many community members developed respiratory symptoms, screening spirometry was usually normal. We hypothesised that forced oscillation testing would identify functional abnormalities undetected by spirometry and that symptom severity would relate to magnitude of abnormalities measured by oscillometry.

A symptomatic cohort $(n=848)$ from the Bellevue Hospital WTC Environmental Health Center was evaluated and compared to an asymptomatic cohort $(n=475)$ from the New York City Department of Health WTC Health Registry. Spirometry and oscillometry were performed. Oscillometry measurements included resistance $\left(R_{5}\right)$ and frequency dependence of resistance $(R 5-20)$.

Spirometry was normal for the majority of subjects (73.2\% symptomatic versus $87.6 \%$ asymptomatic, $\mathrm{p}<0.0001)$. In subjects with normal spirometry, $R_{5}$ and $R_{5}-20$ were higher in symptomatic versus asymptomatic subjects (median (interquartile range) $R_{5} 0.436(0.206)$ versus $0.314(0.129) \mathrm{kPa} \cdot \mathrm{L}^{-1} \cdot \mathrm{s}^{-1}$, $\mathrm{p}<0.001 ; R 5-200.075(0.085)$ versus $\left.0.004(0.042) \mathrm{kPa} \cdot \mathrm{L}^{-1} \cdot \mathrm{s}^{-1}, \mathrm{p}<0.0001\right)$. In symptomatic subjects, $R 5$ and $R 5-20$ increased with increasing severity and frequency of wheeze $(\mathrm{p}<0.05)$.

Measurement of $R 5-20$ correlated with the presence and severity of symptoms even when spirometry was within normal limits. These findings are in accord with small airway abnormalities as a potential explanation of the respiratory symptoms.

@ERSpublications

Small airway dysfunction in a symptomatic population with normal spirometry years after exposure to WTC dust http://ow.ly/TAxxf

Received: July 072015 | Accepted after revision: Oct 122015

Support statement: This study was supported by the American Red Cross Liberty Disaster Relief Fund, the City of New York, US Centers for Disease Prevention and Control (CDC) and National Institute for Occupational Safety and Health (NIOSH) grant 1E11OH009630, CDC-NIOSH Contracts 200-2011-39391, 200-2011-39397 and 200-2011-39413, and National Institute of Environmental Health Sciences grants ES00260 and T32ES07267. Funding information for this article has been deposited with FundRef.

Conflict of interest: None declared.

The content of this work is @ the authors or their employers. Design and branding are @ERS 2015. This article is open access and distributed under the terms of the Creative Commons Attribution Non-Commercial Licence 4.0. 


\section{Introduction}

The destruction of the World Trade Center (WTC) released massive amounts of dust and fumes into the surrounding environment. Community members, as well as rescue and recovery workers, had acute exposure to the initial dust clouds from the collapsing buildings and/or chronic exposure from resuspended dust or from fumes produced by fires that burned for months [1, 2]. Although spirometry has been used to detect lung disease in WTC dust exposed populations, abnormalities have been identified in only a minority of subjects despite development of new-onset and persistent respiratory symptoms. Thus, this population of subjects exposed to WTC dust provided the opportunity to assess the utility of additional screening tests to assess the relationship between the presence and severity of lower respiratory symptoms and functional abnormalities.

Subjects exposed to WTC dust are at risk for development of airway injury at locations ranging from the upper airway to the distal or small airways. Although only 1-2\% of outdoor dust consisted of particles $<2.5 \mu \mathrm{m}$ [1], the extremely large mass of material $\left(\sim 10^{6} \mathrm{t}\right)$ suggested potential for small, as well as large, airway exposure to particulate matter. Indoor dust was composed of an even greater concentration of smaller particles; more than $50 \%$ of particles had diameters $<53 \mu \mathrm{m}$ [3]. Analysis of pathological specimens and induced sputum revealed particles ranging in size from 1 to $50 \mu \mathrm{m}$, confirming inhalation of particles into peripheral airways [4-6].

Although spirometry values were normal in the majority of subjects exposed to WTC dust, airway disease was suggested by longitudinal loss of lung function in firefighters, bronchial hyperreactivity, improvement in lung function in a treatment programme, and/or by airway thickening and air trapping seen with radiologic imaging [7-10]. The absence of an association between spirometry and symptoms in these patients may reflect the limitation of spirometry in detecting functional abnormalities in the small airways (silent zone) of the lung [11-13]. Despite difficulty in identifying small airway abnormalities, their importance in producing respiratory symptoms has been increasingly recognised [14].

The forced oscillation technique (FOT) is a noninvasive test that measures the relationship between pressure and airflow fluctuations applied externally to the respiratory system. FOT has been utilised to provide information about the small airways in patients with asthma and chronic obstructive lung disease [15-18]. We previously demonstrated abnormalities consistent with small airway dysfunction in a case series of WTC dust exposed individuals [19]. This finding was confirmed and reinforced in a large case-control study of community members, in which new-onset and persistent lower respiratory symptoms were associated with both the degree of WTC dust exposure and FOT abnormalities [20, 21].

We hypothesised that small airway abnormalities undetected by spirometry would be demonstrable in a general clinic population seeking evaluation for respiratory symptoms and that the magnitude of the small airway dysfunction would be related to the severity of the respiratory symptoms.

\section{Methods and materials} Study participants

Two groups of participants were studied (symptomatic and asymptomatic cohorts). The symptomatic cohort was recruited from the Bellevue Hospital WTC Environmental Health Center (EHC), a clinic initiated in 2005 for community members with physical or mental health symptoms following WTC dust exposure, which has been previously described [22]. Data were analysed from patients who gave consent for entry in a registry approved by the Institutional Review Board (IRB) of New York University School of Medicine (IRB number 06-1). All individuals underwent a standardised evaluation including a multidimensional symptom and exposure questionnaire, spirometry and FOT assessments. The questionnaire has been adapted from standardised instruments for use following exposure to WTC dust to describe lower respiratory symptoms in terms of severity, onset after September 11, 2001 (9/11), persistence over time, and recent occurrence/frequency [23]. Lower respiratory symptoms were defined as wheeze, dyspnoea, chest tightness or cough that were of new onset after $9 / 11$. Individuals were excluded if they were $<18$ years old, had lung disease or respiratory symptoms prior to $9 / 11$, or had $\geqslant 5$ pack-year tobacco use.

Since the majority of patients in the WTC EHC reported symptoms following 9/11, a population of exposed but asymptomatic subjects was obtained from an external published cohort for comparison [20, 21]. This population included WTC dust exposed residents or local workers enrolled in the New York City Department of Health and Mental Hygiene WTC Health Registry who were asymptomatic for cough, wheezing or shortness of breath before $9 / 11$ and remained asymptomatic on three occasions $2-7$ years after 9/11 ( $\mathrm{n}=475)$. Individuals gave consent under a protocol approved by the IRB of the New York University School of Medicine (IRB number s13-00426). These subjects were never smokers and had no history of cardiopulmonary disease prior to $9 / 11$. These subjects comprised the asymptomatic cohort. 


\section{Lung function measurements}

Spirometry was performed according to published standards (Vmax; CareFusion, Yorba Linda, CA, USA) [24]. Data included forced vital capacity (FVC) and forced expiratory volume in $1 \mathrm{~s}$ (FEV1). Results were classified into normal or abnormal patterns for each patient using their race/ethnicity and published lower limits of normal $[25,26]$.

FOT manoeuvers (Jaeger Impulse Oscillation System; Jaeger, Yorba Linda, CA, USA) were performed in accordance with published recommendations as previously described [10, 20, 27]. Oscillometric measurements were performed in the symptomatic and asymptomatic cohorts with identical equipment for both populations; testing procedures and technician training/supervision was performed by the same investigators. Manoeuvers were performed during tidal breathing in the seated position, with a nose clip in place and with support of the cheeks. A minimum of three trials, lasting $30 \mathrm{~s}$, was performed. Only data from trials with constant tidal volume were analysed. The volume time tracings were inspected to ensure that there were no pauses suggestive of glottis closure and that there was no leak around the mouthpiece [28]. Since the impulse oscillation system analyses 150 impulses over a $30 \mathrm{~s}$ measurement, coherence $>0.70$ at $5 \mathrm{~Hz}$ and 0.85 at $10 \mathrm{~Hz}$ were analysed $[10,29,30]$. Reproducibility between trials (variability $<10 \%$ ) was required $[19,20]$. Data included resistance measured at an oscillating frequency of $5 \mathrm{~Hz}(R 5)$ and frequency dependence of resistance (FDR) calculated as the difference between resistance at $5 \mathrm{~Hz}$ and $20 \mathrm{~Hz}(R 5-20)$. FDR provides a measure of nonuniformity of airflow distribution, which may reflect regional functional abnormalities in the small airways $[15,31,32]$. Oscillometric data were also compared to upper limits of normal derived from published data in normal subjects $[10,15,33]$. The values for the selected upper limits of normal agree with estimates based on recent publications of normative FOT data $[34,35]$.

\section{Statistical analysis}

Counts and percentages were calculated for categorical variables. Medians and interquartile range were calculated for continuous variables. Missing values were excluded from calculations. Associations between study cohorts and categorical variables were tested using the Chi-squared test. For univariate analysis, the nonparametric Kruskal-Wallis test was performed comparing oscillometric values in the symptomatic and asymptomatic cohorts. Multivariate logistic regressions were adopted to assess the association of symptom status with oscillometric measures adjusting for age, body mass index (BMI), race and dust cloud exposure. Relationship between oscillometric values to wheezing severity was analysed by the Jonckheere-Terpstra test to assess the trend of FOT measures across ordered wheezing severity/frequency classes. Analyses were conducted using SAS, version 9.1 (SAS Institute, Cary, NC, USA).

\section{Results}

\section{Patient characteristics}

Between August 2005 and March 2009, valid spirometry and oscillometry data were obtained from 1750 subjects enrolled in the WTC EHC. Subjects were excluded for lung disease or respiratory symptoms preceding $9 / 11(n=400)$, for $a \geqslant 5$-pack-year tobacco history $(n=266)$ or for absence of any lower respiratory symptoms in the month preceding enrolment $(n=236)$. The remaining 848 subjects reported both new-onset lower respiratory symptoms after $9 / 11$ and symptoms that were persistent in the month preceding enrolment. This group comprised the WTC EHC symptomatic cohort (figure 1). The asymptomatic cohort comprised enrolees in the WTC Health Registry who reported being asymptomatic for persistent cough, wheezing and shortness of breath, and had valid spirometry $(n=467)$ and oscillometry data $(\mathrm{n}=441)$.

Table 1 shows the demographic characteristics of the asymptomatic and symptomatic cohorts. Women comprised almost $50 \%$ of both groups. Subjects in the symptomatic cohort were more likely to be Hispanic or African American $(\mathrm{p}<0.0001)$, older $(\mathrm{p}<0.03)$, and overweight (BMI $25-29.9 \mathrm{~kg} \cdot \mathrm{m}^{-2}$ ) or obese $\left(B M I \geqslant 30 \mathrm{~kg} \cdot \mathrm{m}^{-2}\right)(\mathrm{p}<0.001)$, compared to the asymptomatic cohort. Individuals in the symptomatic cohort were also more likely to have been caught in the initial dust clouds created by the collapse of the WTC towers $(\mathrm{p}<0.0005)$

\section{Lung function measurements}

Spirometry results are shown in table 2. Median values for FEV1 and FVC (expressed as \% predicted) for both the asymptomatic and symptomatic cohorts were within normal predicted ranges [26]. However, significantly lower values were noted in the symptomatic compared to the asymptomatic cohort $(\mathrm{p}<0.0001)$ after adjustment for age, race, BMI and dust cloud exposure. FEV1/FVC did not differ between the groups.

Spirometry patterns are shown in table 2. For the asymptomatic cohort, the majority of subjects demonstrated normal spirometry and the percentage of subjects with abnormal spirometry patterns was in 
FIGURE 1 Flow diagram of patient identification for analysis.

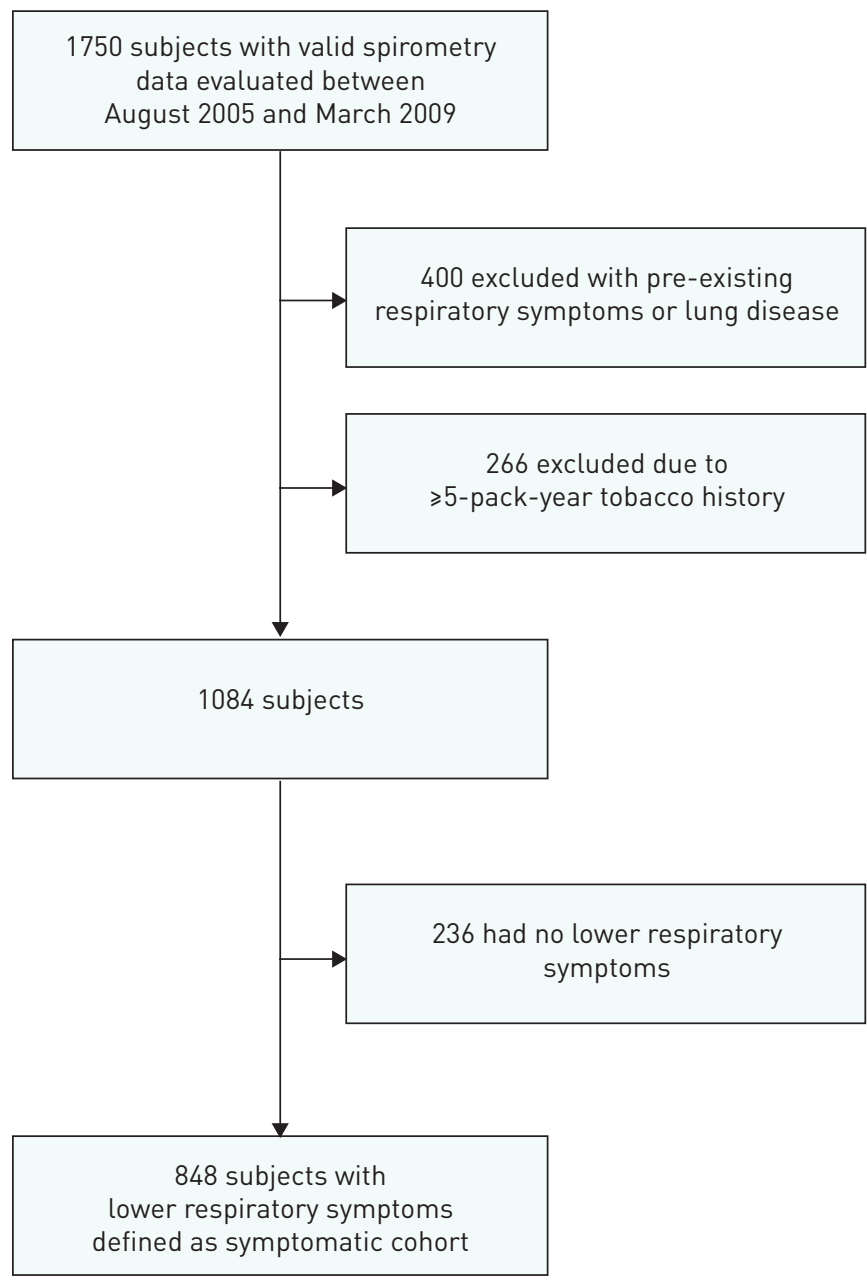

\section{TABLE 1 Demographic characteristics of asymptomatic and symptomatic cohorts}

\begin{tabular}{|c|c|c|c|}
\hline Characteristic & Asymptomatic cohort & Symptomatic cohort & p-value \\
\hline Subjects $\mathrm{n}$ & 475 & 848 & \\
\hline \multicolumn{4}{|l|}{ Sex } \\
\hline Male & 233 (49) & 413 (49) & NS \\
\hline Female & 242 (51) & $435(51)$ & \\
\hline \multicolumn{4}{|l|}{ Race/ethnicity } \\
\hline Hispanic & $22(5)$ & $224(26)$ & $<0.001$ \\
\hline African American & $22(5)$ & $146(17)$ & \\
\hline Caucasian/Asian & $427(91)$ & $478(56)$ & \\
\hline \multicolumn{4}{|l|}{ Age years } \\
\hline $21-39$ & 145 (31) & $205(24)$ & $<0.05$ \\
\hline $40-59$ & $267(56)$ & 504 (59) & \\
\hline$>59$ & $63(13)$ & $139(16)$ & \\
\hline \multicolumn{4}{|l|}{ BMI $\mathrm{kg} \cdot \mathrm{m}^{-2}$} \\
\hline$<25$ & $274(58)$ & $223(26)$ & $<0.001$ \\
\hline $25-30$ & $136(29)$ & $345(41)$ & \\
\hline$>30$ & $62(13)$ & 280 (33) & \\
\hline \multicolumn{4}{|l|}{ Dust cloud } \\
\hline No & $306(65)$ & 458 (55) & $<0.001$ \\
\hline Yes & 167 (35) & $377(45)$ & \\
\hline
\end{tabular}

Data are presented as $\mathrm{n}(\%)$ unless otherwise stated. BMI: body mass index; Ns: not significant. 


\section{TABLE 2 Spirometry results for the asymptomatic and symptomatic cohorts}

\begin{tabular}{lccc} 
& $\begin{array}{c}\text { Asymptomatic } \\
\text { cohort }\end{array}$ & $\begin{array}{c}\text { Symptomatic } \\
\text { cohort }\end{array}$ & p-value \\
\hline $\begin{array}{l}\text { Spirometry parameters median (interquartile range) } \\
\text { FEV1\% predicted }\end{array}$ & $98.2(16.7)$ & $91.4(19.7)$ & $<0.0001$ \\
FVC \% predicted & $99.4(15.6)$ & $92.3(20.4)$ & $<0.0001$ \\
FEV1/FVC \% & $79.3(8.2)$ & $80.0(8.0)$ & NS \\
Spirometry pattern n (\%) & $409(87.6)$ & $621(73.2)$ & $<0.0001$ \\
Normal & $30(6.4)$ & $60(7.1)$ & NS \\
Obstructed & $26(5.6)$ & $147(17.3)$ & $<0.0001$ \\
Low FVC & $2(0.4)$ & $20(2.4)$ & $<0.01$ \\
Obstructed and low FVC & & & \\
\hline FEV1: forced expiratory volume in 1 s; FVC: forced vital capacity; NS: not significant. ${ }^{\#}:$ valid spirometry \\
data were not available in eight subjects from the asymptomatic cohort. & &
\end{tabular}

accord with expectations for a healthy population. For the symptomatic cohort, the majority of subjects (73.2\%) demonstrated normal spirometry despite persistent respiratory symptoms. Abnormal spirometry pattern was noted in only $27 \%$ of the symptomatic cohort and the predominant abnormality was a low FVC pattern, in accord with prior publications in WTC-exposed individuals. The rate of abnormal spirometry was significantly different in the symptomatic compared to the asymptomatic cohort $(\mathrm{p}<0.0001)$, with the proportion of subjects with a low FVC pattern being significantly higher in the symptomatic cohort $(17 \%$ versus $6 \%, \mathrm{p}<0.0001)$.

Oscillometry results are shown in table 3 . Both $R 5$ and $R 5-20$ were elevated in the symptomatic compared to the asymptomatic cohort $(\mathrm{p}<0.0001)$. Since obesity is associated with abnormal oscillometry [20, 36], we examined oscillometric parameters in the asymptomatic and symptomatic WTC EHC Cohorts after stratifying by BMI category (figure 2). As anticipated, median $R 5$ and R5-20 increased with increasing BMI in both groups. Despite the increase in FOT measurements with BMI, median values for $R 5$ and $R 5-20$ were significantly higher in the symptomatic compared with the asymptomatic cohort across all BMI categories $(\mathrm{p}<0.0001$ for all comparisons $)$.

\section{Oscillometry measurements in subjects with a normal spirometry pattern}

Oscillometric parameters were analysed in the cohorts after categorising subjects based on their initial spirometry results. Figure 3 illustrates oscillometric data from subjects with normal spirometry in the asymptomatic and symptomatic cohorts. Despite spirometry measurements within normal limits, median $R 5$ remained elevated in the symptomatic compared to the asymptomatic cohort (median (interquartile range) $0.436(0.206)$ versus $\left.0.314(0.129) \mathrm{kPa} \cdot \mathrm{L}^{-1} \cdot \mathrm{s}^{-1}, \mathrm{p}<0.0001\right)$. Similar results were demonstrated for $R 5-20$ in subjects with normal spirometry $\left(0.075(0.085)\right.$ versus $\left.0.004(0.042) \mathrm{kPa} \cdot \mathrm{L}^{-1} \cdot \mathrm{s}^{-1}, \mathrm{p}<0.0001\right)$. When data were analysed with respect to the upper limit of normal, elevated $R 5$ and $R 5-20$ were noted in the majority of subjects despite normal spirometry (62\% and $50 \%$, respectively). In contrast, analysis of midexpiratory airflow rates demonstrated abnormal values in only $14 \%$ of these subjects.

\section{Relationship of symptoms with oscillometry}

We examined oscillometric measurements and symptom severity in the symptomatic cohort. No relationship was observed between cough and dyspnoea to oscillometry (data not shown); however, a relationship to wheeze was noted (table 4). Wheeze was characterised by self-report of degree of severity

\section{TABLE 3 Oscillometry results for the asymptomatic and symptomatic cohorts}

\begin{tabular}{lcccc}
$\begin{array}{l}\text { Oscillometry } \\
\text { parameters }\end{array}$ & $\begin{array}{c}\text { Upper limit of } \\
\text { normal }\end{array}$ & $\begin{array}{c}\text { Asymptomatic } \\
\text { cohort }^{\#}\end{array}$ & $\begin{array}{c}\text { Symptomatic } \\
\text { cohort }\end{array}$ & p-value \\
\hline $\begin{array}{l}\mathbf{R}_{5} \mathrm{kPa} \cdot \mathrm{L}^{-1} \cdot \mathbf{s}^{-1} \\
\mathbf{R}_{\mathbf{5}} \mathbf{2 0} \mathrm{kPa} \cdot \mathrm{L}^{-1} \cdot \mathbf{s}^{-1}\end{array}$ & 0.388 & $0.318(0.140)$ & $0.450(0.228)$ & $<0.01$ \\
\hline
\end{tabular}

Data are presented as median (interquartile range) unless otherwise stated. $R 5$ : resistance at an oscillating frequency of $5 \mathrm{~Hz} ; R 5-20$ : difference in resistances measured at 5 and $20 \mathrm{~Hz}$. " ${ }^{\text {: }}$ valid data were not available in 34 subjects from the asymptomatic cohort. 

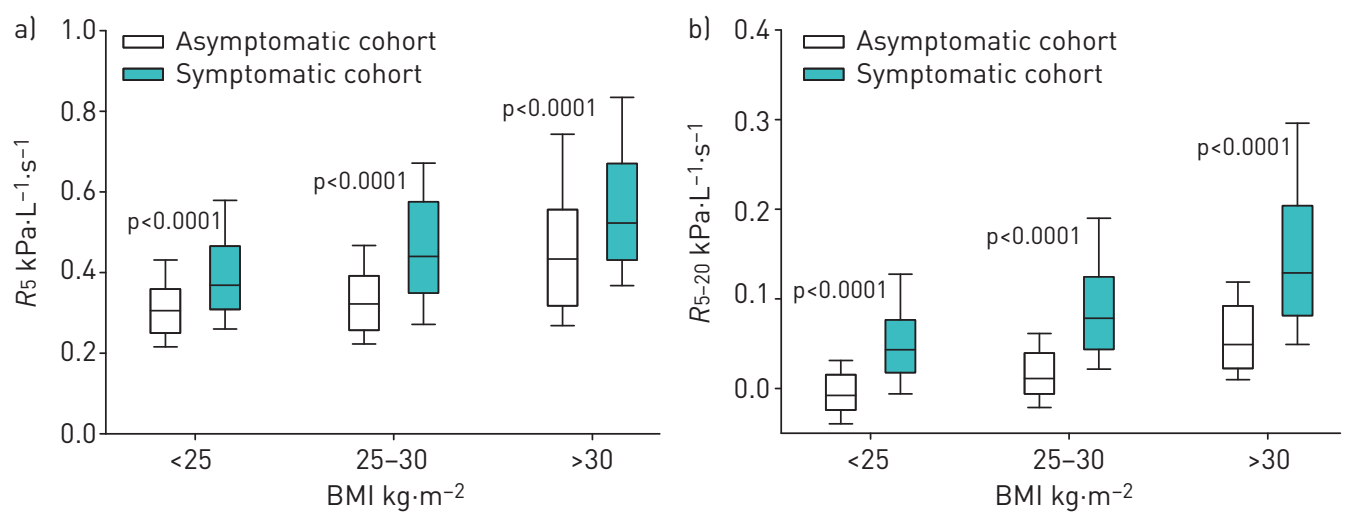

FIGURE 2 a) Resistance at an oscillating frequency of $5 \mathrm{~Hz}\left(R_{5}\right)$ and b) difference in resistances measured at 5 and $20 \mathrm{~Hz}\left(R_{5}-20\right)$ are plotted by body mass index (BMI) status for the asymptomatic versus symptomatic cohorts. Boxes represent 25th, 50th and 75th percentiles for $R_{5}$ and $R_{5-20}$ distribution. Whiskers represent fifth and 95th percentiles.
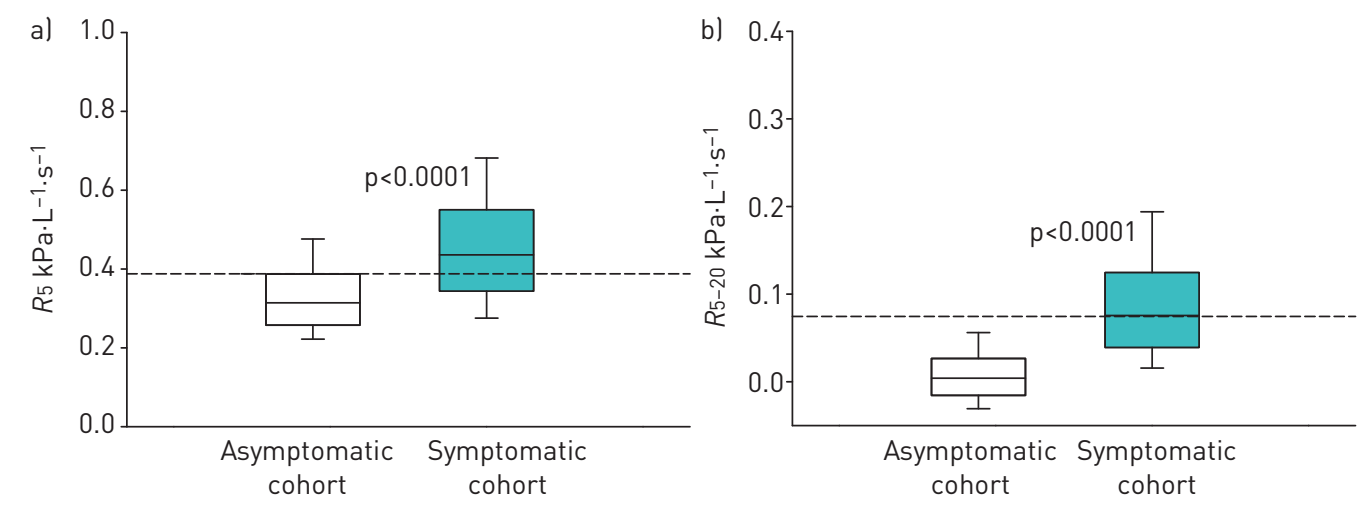

FIGURE 3 a) Resistance at an oscillating frequency of $5 \mathrm{~Hz}\left(R_{5}\right)$ and b) difference in resistances measured at 5 and $20 \mathrm{~Hz}\left(R_{5-20}\right)$ are plotted for individuals with normal spirometry from the asymptomatic versus symptomatic cohorts. Boxes represent 25 th, 50 th and 75 th percentiles for $R 5$ and $R 5-20$ distribution. Whiskers represent fifth and 95th percentiles. $p$-values were adjusted for age, race and body mass index.

\begin{tabular}{|c|c|c|c|}
\hline & Subjects $\mathbf{n}$ & $R_{5} \mathrm{kPa} \cdot \mathrm{L}^{-1} \cdot \mathrm{s}^{-1}$ & $R 5-20 \mathrm{kPa} \cdot \mathrm{L}^{-1} \cdot \mathrm{s}^{-1}$ \\
\hline \multicolumn{4}{|c|}{ Wheeze severity } \\
\hline None & 502 & $0.447(0.212)$ & 0.074 (0.087) \\
\hline Mild & 137 & $0.458(0.260)$ & $0.085(0.123)$ \\
\hline Moderate & 128 & $0.473(0.233)$ & $0.102(0.121)$ \\
\hline Severe & 67 & $0.503(0.301)$ & $0.113(0.129)$ \\
\hline p-value & & 0.001 & $<0.0001$ \\
\hline \multicolumn{4}{|c|}{ Wheeze frequency days per week } \\
\hline $0-1$ & 524 & $0.441(0.220)$ & $0.076(0.088)$ \\
\hline $2-6$ & 194 & $0.461(0.218)$ & $0.086(0.117)$ \\
\hline 7 & 100 & $0.510(0.278)$ & $0.126(0.122)$ \\
\hline$p$-value ${ }^{\#}$ & & $<0.01$ & 0.0001 \\
\hline \multicolumn{4}{|c|}{$\begin{array}{l}\text { Data are presented as median (interquartile range) unless otherwise stated. R5: resistance at } \\
\text { an oscillating frequency of } 5 \mathrm{~Hz} ; R 5-20 \text { : difference in resistances measured at } 5 \text { and } 20 \mathrm{~Hz} \text {. } \\
\text { \# : Jonckheere-Terpstra test. }\end{array}$} \\
\hline
\end{tabular}


(mild, moderate or severe) and frequency in the 4 weeks prior to enrolment. For the symptomatic cohort, a significant trend was demonstrated with increasing values for both $R 5$ and $R 5-20$ in relation to increasing severity of wheeze. Similarly, both $R_{5}$ and $R_{5-20}$ increased in relation to frequency of wheeze ( $\mathrm{p}<0.01$ for all analyses).

The association of oscillometry measurements with frequency and severity of wheeze was also evaluated in the subgroup of subjects in the symptomatic cohort with normal spirometry (table 5). Increasing values of R5-20 were significantly associated with increasing severity and frequency of wheeze. In contrast, no association was found between $R 5$ and either severity or frequency of wheeze.

\section{Discussion}

We examined the utility of adding oscillometry to spirometry in evaluation of new-onset and persistent lower respiratory symptoms in a large cohort of WTC dust exposed community members. Whereas abnormal spirometry was evident in a minority of the WTC EHC symptomatic cohort, oscillometry measurements were abnormal in most. Abnormalities in oscillometry were characterised by elevations in both respiratory resistance $(R 5)$ and FDR $(R 5-20)$. Since the presence of FDR is consistent with nonuniformity of airflow distribution and regional functional abnormalities in the small airways $[15,31,32]$ and since FDR was detected even when spirometry was within normal limits, these data suggest isolated injury to the small airways in many of these symptomatic subjects. Importantly, oscillometry measurements increased with both severity and frequency of wheeze, even when the analysis was limited to those with normal spirometry. These findings suggest that functional abnormalities isolated to the small airways may provide an explanation for presence and severity of lower respiratory symptoms.

An understanding of the physiological abnormalities associated with respiratory symptoms following exposure to WTC dust has been elusive, since the majority of subjects demonstrate normal spirometry and chest radiographs $[7,22,37,38]$. A role for small airway dysfunction was initially suggested by several studies using forced oscillation [33]. FDR on oscillometry and frequency dependence of compliance on oesophageal manometry was shown in a case series of subjects with exposure to WTC dust [19]. More recently, we linked the development of lower respiratory symptoms to both intensity of WTC dust exposure and abnormal FDR in subjects enrolled in the WTC Health Registry [20,21]. Our current study in the Bellevue Hospital WTC EHC supports and extends these findings by demonstrating evidence for small airway dysfunction not detectable by spirometry (either by FEV1 or by midexpiratory airflow rate) in a general population seeking medical care for lower respiratory symptoms following exposure to WTC dust. Moreover, for the subjects with abnormal spirometry in the present study, the predominant abnormality was reduction in vital capacity with normal FEV1/FVC, a pattern that has recently been linked to small airway dysfunction following WTC dust exposure [10]. Lastly, the present study reinforces the link between small airway function and symptoms by demonstrating an association between FOT parameters and severity of wheeze.

The abnormalities in oscillometry parameters detected in the WTC EHC symptomatic population are consistent with injury to small airways. Oscillometry parameters included $R 5$, a measure of respiratory

\begin{tabular}{|c|c|c|c|}
\hline & Subjects $\mathbf{n}$ & $R_{5} \mathrm{kPa} \cdot \mathrm{L}^{-1} \cdot \mathrm{s}^{-1}$ & $R 5-20 \mathrm{kPa} \cdot \mathrm{L}^{-1} \cdot \mathrm{s}^{-1}$ \\
\hline \multicolumn{4}{|c|}{ Wheeze severity } \\
\hline None & 384 & $0.429(0.200)$ & $0.070(0.081)$ \\
\hline Mild & 97 & $0.424(0.218)$ & $0.080(0.077)$ \\
\hline Moderate & 80 & $0.457(0.231)$ & $0.078(0.088)$ \\
\hline Severe & 50 & $0.496(0.191)$ & $0.097(0.101)$ \\
\hline p-value $\#$ & & NS & 0.03 \\
\hline \multicolumn{4}{|c|}{ Wheeze frequency days per week } \\
\hline $0-1$ & 400 & $0.432(0.206)$ & $0.071(0.088)$ \\
\hline $2-6$ & 129 & $0.437(0.216)$ & 0.077 (0.069) \\
\hline 7 & 70 & $0.492(0.265)$ & $0.100(0.118)$ \\
\hline$p$-value $\#$ & & NS & 0.05 \\
\hline
\end{tabular}


resistance, and R5-20, a measure of FDR. FDR has been attributed to nonuniform distribution of airflow in the distal lung $[15,31,32]$ and has been shown to correlate with assessment of frequency dependence of compliance using oesophageal manometry [39, 40], an established marker of small airway dysfunction. Biological plausibility for small airway injury is supported by demonstration of particles in the lower airways in both pathological specimens and induced sputum [4-6]. The presence of small airway injury in WTC-exposed populations is further supported by demonstration of air trapping on either computed tomography imaging and/or plethysmography [7-9]. In addition, pathological specimens have demonstrated objective signs of small airway and parenchymal lung injury [5]. In the present study, abnormal resistance and FDR were demonstrated in the symptomatic cohort. This observation, coupled with the finding that FVC and FEV1 remained in the normal range, is consistent with a location of injury that is more distal than that detectable by spirometry. Although FDR may reflect abnormalities in elements of the distal lung unit beyond the airways, the correlation with wheezing indicates a significant component of small airway injury in this cohort.

The present study demonstrated the novel association between oscillometry measurements and self-reported lower respiratory symptoms in the symptomatic cohort [14]. While no relationship was demonstrable for cough or dyspnoea, a strong relationship was seen between magnitude of FDR with both severity and frequency of wheeze, a marker of airway reactivity. These findings are in accord with prior demonstration that elevated blood eosinophils in WTC dust exposed subjects are associated with both the presence and self-reported frequency and severity of wheeze but not with either cough or dyspnoea [41]. Although this prior study demonstrated an association between wheeze and presence of obstruction on spirometry, wheezing was also noted in approximately $33 \%$ of subjects with normal spirometry [41]. The present study extends these observations by demonstrating that oscillometry measurements of FDR remained significantly associated with frequency and severity of wheeze in the subjects with normal spirometry. Although these associations do not prove causality, a previous study during methacholine challenge testing demonstrated that the onset of respiratory symptoms during induced bronchoconstriction may occur simultaneous with the onset of small airway abnormalities on FOT testing even when spirometry remains unchanged [42].

This study was designed to examine the link between the respiratory symptoms and physiological abnormalities but not to detailed WTC dust exposure. Previous studies have demonstrated a relationship between severity of WTC dust exposure and/or exposure to the dust cloud, and both development of respiratory symptoms and physiological abnormalities in the small airways [20,21]. In accord with this finding, exposure to the dust cloud was noted more frequently in the symptomatic versus the asymptomatic cohort.

There are several limitations to this study. FOT data was not corrected for lung volume and high values for resistance would occur if functional residual capacity (FRC) was reduced. Although FRC was not measured in this study, we previously demonstrated that FRC remained in the normal range following exposure to WTC dust [19]. In addition, while the most likely cause for a reduced FRC in the present study is obesity, it is unlikely to have influenced the conclusions since symptomatic subjects demonstrated higher resistance and more FDR across all categories of BMI. An additional consideration relates to the potential for upper airway abnormalities and/or glottic closure, which could contribute to both symptoms and abnormal FOT [43]. However, in the present study, there was no evidence for upper airway dysfunction on the inspiratory portion of the flow-volume curve and the FOT technique was specifically evaluated to exclude glottis closure during testing [28]. Lastly, an asymptomatic population within the WTC EHC could not be identified because patients were self-referred for evaluation of symptoms. Therefore, we used an external asymptomatic population that had undergone similar measurements as part of a collaborative study of WTC health effects [20]. These subjects either lived or worked in lower Manhattan and may have sustained some exposure to WTC dust. Spirometry and oscillometry measurements were performed within a similar time frame with similar equipment, techniques and personnel. Oscillometry values in this population were within the normal range when compared to published data, supporting that these subjects had normal airway function despite WTC dust exposure [10, 15, 33-35]. Although demographic characteristics differed between the symptomatic and the asymptomatic cohort, the difference in oscillometry measurements remained even after adjustment for these differences. Moreover, in analyses limited to the symptomatic cohort, a relationship was observed between the magnitude of small airway dysfunction and severity and frequency of wheeze. Although symptoms in these subjects were assessed by self report, oscillometry measurements are not influenced by patient effort and were obtained independently.

In summary, addition of forced oscillation to routine assessment of spirometry in the clinical setting uncovered abnormalities in lung function in a persistently symptomatic population with normal spirometry many years after exposure to the $9 / 11$ disaster. The present study highlights that assessment of small airway 
function can be performed routinely in the large-scale clinical setting. Importantly, the study suggests that small airway assessment has an important role in characterising symptoms not explained by spirometry. The finding of abnormal oscillometry and its correlation to symptom severity, even in the setting of normal spirometry, is in accord with the presence of small airway abnormalities as a potential explanation of the lower respiratory symptoms. The presence of small airway abnormality associated with persistence of lower respiratory symptoms many years after exposure to WTC dust suggests persistent airway disease.

\section{References}

1 Lioy PJ, Weisel CP, Millette JR, et al. Characterization of the dust/smoke aerosol that settled east of the World Trade Center (WTC) in lower Manhattan after the collapse of the WTC 11 September 2001. Environ Health Perspect 2002; 110: 703-714.

2 Offenberg JH, Eisenreich SJ, Gigliotti CL, et al. Persistent organic pollutants in dusts that settled indoors in lower Manhattan after September 11, 2001. J Expo Anal Environ Epidemiol 2004; 14: 164-172.

3 Yiin LM, Millette JR, Vette A, et al. Comparisons of the dust/smoke particulate that settled inside the surrounding buildings and outside on the streets of southern New York City after the collapse of the World Trade Center, September 11, 2001. J Air Waste Manag Assoc 2004; 54: 515-528.

4 Rom WN, Weiden M, Garcia R, et al. Acute eosinophilic pneumonia in a New York City firefighter exposed to World Trade Center dust. Am J Respir Crit Care Med 2002; 166: 797-800.

5 Caplan-Shaw CE, Yee H, Rogers L, et al. Lung pathologic findings in a local residential and working community exposed to World Trade Center dust, gas, and fumes. J Occup Environ Med 2011; 53: 981-991.

6 Fireman EM, Lerman Y, Ganor E, et al. Induced sputum assessment in New York City firefighters exposed to World Trade Center dust. Environ Health Perspect 2004; 112: 1564-1569.

7 Prezant DJ, Weiden M, Banauch GI, et al. Cough and bronchial responsiveness in firefighters at the World Trade Center site. N Engl J Med 2002; 347: 806-815.

8 Mendelson DS, Roggeveen M, Levin SM, et al. Air trapping detected on end-expiratory high-resolution computed tomography in symptomatic World Trade Center rescue and recovery workers. J Occup Environ Med 2007; 49: 840-845.

9 Weiden MD, Ferrier N, Nolan A, et al. Obstructive airways disease with air trapping among firefighters exposed to World Trade Center dust. Chest 2010; 137: 566-574.

10 Berger KI, Reibman J, Oppenheimer BW, et al. Lessons from the world trade center disaster: airway disease presenting as restrictive dysfunction. Chest 2013; 144: 249-257.

11 Macklem PT. The physiology of small airways. Am J Respir Crit Care Med 1998; 157: S181-S183.

12 Mead J. The lung's "quiet zone". N Engl J Med 1970; 282: 1318-1319.

13 Pedley TJ, Schroter RC, Sudlow MF. The prediction of pressure drop and variation of resistance within the human bronchial airways. Respir Physiol 1970; 9: 387-405.

14 van der Wiel E, ten Hacken NH, Postma DS, et al. Small-airways dysfunction associates with respiratory symptoms and clinical features of asthma: a systematic review. J Allergy Clin Immunol 2013; 131: 646-657.

15 Goldman MD, Saadeh C, Ross D. Clinical applications of forced oscillation to assess peripheral airway function. Respir Physiol Neurobiol 2005; 148: 179-194.

16 King GG. Cutting edge technologies in respiratory research: lung function testing. Respirology 2011; 16: 883-890.

17 Kaminsky DA. What does airway resistance tell us about lung function? Respir Care 2012; 57: 85-96.

18 Bickel S, Popler J, Lesnick B, et al. Impulse oscillometry: interpretation and practical applications. Chest 2014; 146: 841-847.

19 Oppenheimer BW, Goldring RM, Herberg ME, et al. Distal airway function in symptomatic subjects with normal spirometry following World Trade Center dust exposure. Chest 2007; 132: 1275-1282.

20 Friedman SM, Maslow CB, Reibman J, et al. Case-control study of lung function in World Trade Center Health Registry area residents and workers. Am J Respir Crit Care Med 2011; 184: 582-589.

21 Maslow CB, Friedman SM, Pillai PS, et al. Chronic and acute exposures to the world trade center disaster and lower respiratory symptoms: area residents and workers. Am J Public Health 2012; 102: 1186-1194.

22 Reibman J, Liu M, Cheng Q, et al. Characteristics of a residential and working community with diverse exposure to World Trade Center dust, gas, and fumes. J Occup Environ Med 2009; 51: 534-541.

23 Revicki DA, Leidy NK, Brennan-Diemer F, et al. Integrating patient preferences into health outcomes assessment: the multiattribute Asthma Symptom Utility Index. Chest 1998; 114: 998-1007.

24 Miller MR, Hankinson J, Brusasco V, et al. Standardisation of spirometry. Eur Respir J 2005; 26: 319-338.

25 Pellegrino R, Viegi G, Brusasco V, et al. Interpretative strategies for lung function tests. Eur Respir J 2005; 26: 948-968.

26 Hankinson JL, Odencrantz JR, Fedan KB. Spirometric reference values from a sample of the general U.S population. Am J Respir Crit Care Med 1999; 159: 179-187.

27 Oostveen E, MacLeod D, Lorino $\mathrm{H}$, et al. The forced oscillation technique in clinical practice: methodology, recommendations and future developments. Eur Respir J 2003; 22: 1026-1041.

28 Bikov A, Pride NB, Goldman MD, et al. Glottal aperture and buccal airflow leaks critically affect forced oscillometry measurements. Chest 2015; 148: 731-738.

29 Miller TKIII, Pimmel RL. Standard errors on respiratory mechanical parameters obtained by forced random excitation. IEEE Trans Biomed Eng 1983; 30: 826-832.

30 Komarow HD, Myles IA, Uzzaman A, et al. Impulse oscillometry in the evaluation of diseases of the airways in children. Ann Allergy Asthma Immunol 2011; 106: 191-199.

31 Fredberg JJ, Mead J. Impedance of intrathoracic airway models during low-frequency periodic flow. J Appl Physiol 1979; 47: 347-351.

32 Bates JH, Lutchen KR. The interface between measurement and modeling of peripheral lung mechanics. Respir Physiol Neurobiol 2005; 148: 153-164.

33 Skloot G, Goldman M, Fischler D, et al. Respiratory symptoms and physiologic assessment of ironworkers at the World Trade Center disaster site. Chest 2004; 125: 1248-1255. 
34 Newbury W, Crockett A, Newbury J. A pilot study to evaluate Australian predictive equations for the impulse oscillometry system. Respirology 2008; 13: 1070-1075.

35 Oostveen E, Boda K, van der Grinten CP, et al. Respiratory impedance in healthy subjects: baseline values and bronchodilator response. Eur Respir J 2013; 42: 1513-1523.

36 Zerah F, Harf A, Perlemuter L, et al. Effects of obesity on respiratory resistance. Chest 1993; 103: 1470-1476.

37 Herbert R, Moline J, Skloot G, et al. The world Trade Center disaster and the health of workers: five-year assessment of a unique medical screening program. Environ Health Perspect 2006; 114: 1853-1858.

38 Reibman J, Lin S, Hwang SA, et al. The World Trade Center residents' respiratory health study: new-onset respiratory symptoms and pulmonary function. Environ Health Perspect 2005; 113: 406-411.

39 Oppenheimer BW, Goldring RM, Berger KI. Distal airway function assessed by oscillometry at varying respiratory rate: comparison with dynamic compliance. COPD 2009; 6: 162-170.

40 Kjeldgaard JM, Hyde RW, Speers DM, et al. Frequency dependence of total respiratory resistance in early airway disease. Am Rev Respir Dis 1976; 114: 501-508.

41 Kazeros A, Maa MT, Patrawalla P, et al. Elevated peripheral eosinophils are associated with new-onset and persistent wheeze and airflow obstruction in world trade center-exposed individuals. J Asthma 2013; 50: 25-32.

42 Segal LN, Goldring RM, Oppenheimer BW, et al. Disparity between proximal and distal airway reactivity during methacholine challenge. COPD 2011; 8: 145-52.

43 de la Hoz RE, Shohet MR, Bienenfeld LA, et al. Vocal cord dysfunction in former World Trade Center (WTC) rescue and recovery workers and volunteers. Am J Ind Med 2008; 51: 161-165. 